rectangle MNTS. With latitude and longitude arcs drawn sufficiently elosely on the sphere to form a suitable scale, this gives a very easy estimate of the difference of hue; similarly, in the case of any two colour vectors $O P, O P^{\prime}$.

The outstanding difficulty, referred to by Dr. Wright, of getting a uniform chromaticity scale, remains. But it seems to me that the fact of the angular spread of the spectrum curve of sensation, amounting to $240^{\circ}$ in the sensation space, as compared with $90^{\circ}$, or a little more, in the stimulus plane space, may indicate a considerable advantage.

In all adjustments taking place in the work of colour matching, it is equalization of sensation (hue or saturation) that is the direct aim. So this method. of representation is very direct. Whether it be really superior to the representation used hitherto or not, I cannot judge, from want of familiarity with the practical needs. It would be of value to have Dr. Wright's view on the whole matter.

University College,

W. Peddie. Dundee.

NATURE, 146, 155 (1940)

NATURE, 124, 791 (1929).

IT would, as Prof. Peddie suggests, be possible to approach the problem of a uniform chromaticity scale from the point of view of the sensation rather than the stimulus. An investigation ${ }^{1}$ somewhat along these lines is in fact in progress in connexion with the spacing of the colours on the Munsell system. But for ordinary colorimetric purposes, it is desirable that the distribution of colours should possess the geometrical relations characteristic of the trichromatic colour triangle, and to ensure that, the stimulus approach appears to be essential.

Further, I fear that the laws relating stimulus and sensation are so open to question, that a colour solid based on them would be unlikely to stand the strain of practical usage; instead, the solid would have to be derived from fresh experimental observations of colour differences, as in the case of the Munsell system. It might happen that identical colour distributions would be obtained whether the stimulus or the sensation approach were employed, but I can see no theoretical reason why this should occur, nor, so far as $\mathrm{I}$ know, is there any experimental evidence suggesting such a fortunate contingency.

W. D. Wright.

${ }^{1}$ Newhall, S. M., Amer. J. Psych., 52, 394 (1939).

\section{Formation of Insoluble Digitonides of Cholesterol Derivatives}

IN the course of an investigation of 6-chloro-3benzoyloxy- $\triangle^{4}$-cholestene ${ }^{1}$, we have isolated a mono-

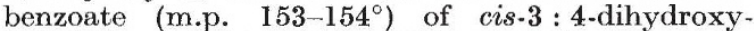
$\triangle^{5}$-cholestene (I) which differs considerably from the monobenzoate (m.p. 209-210 ) of the cis-diol prepared by the method of Rosenheim and Starling ${ }^{2}$; the latter has been accorded the 3-monobenzoate structure on the seemingly substantial evidence that the $c i s$-diol (I) gives an insoluble digitonide, whereas the monobenzoate, m.p. $209-210^{\circ}$, fails to do so. To test the implication that the new ester, m.p. $153-154^{\circ}$, is the 4-monobenzoate, its reaction with digitonin was examined. It fails to give a digitonide using standardized conditions which effect immediate precipitation of the digitonides of cholesterol and the cis-diol (I). It follows that the formation of one of the monobenzoates of the cis-diol has been accom-

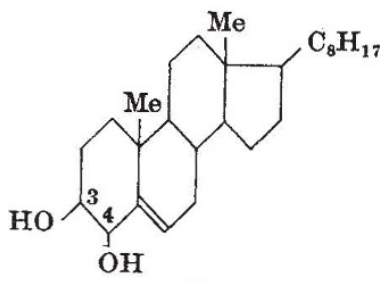

(I)

panied by the migration of a benzoyl-group from the $\mathrm{C}_{3^{-}}$to the $\mathrm{C}_{4}$-hydroxyl, and although such migration appears to be less likely in the case of the monobenzoate m.p. $209-210^{\circ}$, the exact location of the esterified hydroxyl group in the mono-esters ${ }^{3}$ remains to be rigidly established. Furthermore, it is clear that the introduction of a $\mathrm{C}_{4}$-cis-benzoyloxygroup into cholesterol prohibits the digitonin reaction. F. S. SPrInG.

G. Swarn.

The University

Manchester.

Nov. 1.

1 Spring, F. S., and Swain, G., J. Chem. Soc., 1356 (1939)

2 J. Chem. Soc., 377 (1937).

(Added in proof). Dr. O. Rosenheim informs us (private communication) that he has prepared the hitherto unknown 4(?)-monoacetate of the cis-diol which, as we find is the case with the 3(?)-monoacetate, fails to give an insoluble digitonide.

\section{A Non-Historical Eclipse}

IN John Evelyn's "Diary", under the date October 14, 1688, there is a record of an eclipse of the sun. Now it is quite true that an eclipse took place, but this was not visible in any part of Europe. The central line passed very far south, and even the limit of the partial phase came only a few degrees north of the equator near its farthest extension to the north and west.

The reference to the eclipse consists of a sentence of only six words, which has much of the appearance of being a subsequent insertion. That is probably what it is, as the diarist can only be stating what some other person told him, and thus there is reason for concluding that some traveller from rather distant regions supplied the information at a later date. It is difficult to think of an answer to the problem of who the observer can have been.

The rest of the entry in the Diary states that the day was a Sunday, and prayers were offered in the churches for protection from invasion. This naturally attracts attention, but the reference is merely to Prince William of Orange, for whose arrival many Englishmen "were passionately longing".

These are Evelyn's own words, and the use of the past tense is further evidence of the fact that he was making insertions at a later date. On the third Sunday after that, the Prince, favoured by a "protestant wind", sailed into a British seaport; and he found the men of Devon willing to give him plentiful assistance in landing.

Christchurch,

C. J. Westland.

New Zealand. Sept. 1. 